\title{
Recruitment and retention of general practitioners in England: a survey of health authorities and directors of postgraduate GP education
}

Brenda Leese, Ruth Young and Bonnie Sibbald National Primary Care Research and Development Centre, University of Manchester, Manchester, UK

\begin{abstract}
Problems with regard to the recruitment and retention of general practitioners (GPs) have been largely attributed to disquiet over ongoing government health reforms, together with increased administrative and surgery workloads, low morale and stress. This study aimed to provide empirical evidence of the scale of the workforce crisis in GP recruitment and retention, and the type of initiatives being developed to address local problems. Postal questionnaires were sent to directors of primary care in all 100 health authorities in England, and to directors of postgraduate GP education. Problems associated with recruitment and retention were mainly confined to less attractive locations, primarily deprived urban areas. Sources of new recruits mainly consisted of local training schemes. Numerous initiatives had been set up to address local problems, but these tended to be piecemeal and small scale. Although there was widespread awareness of problems with regard to the recruitment and retention of GPs, there was little evidence of co-ordinated approaches to offset future problems.
\end{abstract}

Key words: general practitioners; initiatives; recruitment; retention; workforce

\section{Introduction}

The view that the general practitioner profession is facing a widespread and deepening workforce crisis has been expressed in numerous reports (Review Body on Doctors' and Dentists' Remuneration, 1996, 1998; Royal College of General Practitioners, 1997; British Medical Association, 1998; Carlowe 1998; General Medical Services Committee, 1998; McKinnon et al., 1999). Not only are medical graduates reportedly less interested in becoming general practitioners (GPs), but those who complete GP vocational training appear to be more reluctant to move directly into practice (General Medical Services Committee, 1996; Young and Leese, 1999). Such trends have been

Address for correspondence: Dr Brenda Leese, Centre for Research in Primary Care, University of Leeds, Hallas Wing, 71-75 Clarendon Road, Leeds LS2 9PL, UK. Email: b.leese@leeds.ac.uk attributed largely to GPs' disquiet over ongoing government health reforms, low morale, increased administrative and surgery workloads and stress (Calman and Williams, 1995; Kernick, 1995; Chambers et al., 1996; Leese and Young, 1999).

We here report the findings of a postal survey of all health authorities (HAs) and directors of postgraduate GP education in England conducted during 1998. The objective of the survey was to provide more sophisticated empirical evidence than was previously available on firstly the scale and nature of GP recruitment and retention problems, and secondly the types of initiatives and approaches that were being developed to address these problems.

\section{Methods}

In March 1998 separate postal questionnaires were mailed to directors of primary care in all 100 
English HAs and to directors of postgraduate GP education. The latter covered issues specific to GP registrars and vocational training, whereas the HA questionnaire covered recruitment and retention across the entire GP workforce, including principals, nonprincipals and registrars. Copies of HAs' workforce plans and descriptions of the initiatives that were being developed to improve GP recruitment and/or retention were also requested. In addition, the opportunity was provided in open-ended questions for respondents to expand on their views about the local situation, although not all of them took this opportunity. The original survey was followed by four rounds of telephone reminders to nonresponders (the last in December 1998), with replacement questionnaires being sent as appropriate.

\section{Results}

\section{Response rates}

A total of 73 HAs (73\%) returned the survey, of which 22 HAs also sent a copy of their workforce plan and six others provided information about workforce initiatives. One additional HA provided its workforce plan alone. For directors of postgraduate GP education, the response rate was $61 \%$ (11 respondents). One other respondent outlined his own analysis of the situation. However, not all of the questions were answered in all of the questionnaires, so that in some cases the numbers do not add up to the total number returned. Table 1 shows the response rates categorized by NHS regions. An additional analysis was undertaken to determine whether the respondent HAs differed from the nonrespondents in terms of deprivation levels measured by the Under-Privileged Area (UPA) score. It was found that $45 \%$ of the 100 HAs in England had a positive UPA score, compared with $53 \%$ (39) of the survey respondents, indicating that the responding HAs had higher levels of deprivation than HAs overall.

\section{The scale of GP workforce shortages}

\section{$G P$ registrars and training practices}

Nine $(81 \%)$ of the 11 responding directors of postgraduate GP education said that the overall numbers of training practices were adequate to meet local workforce needs. However, four (36\%) said that there were specific, mainly deprived, areas of HAs with insufficient training practices.

Seven $(63.6 \%)$ of the directors of postgraduate GP education also stated that HAs in their area had problems in recruiting GP registrars. The vacancy rates for training places they reported ranged from $6.8 \%$ to $42.3 \%$. The total rate of GP registrar posts that were vacant across all areas was $24.9 \%$. Overall, 31 HAs $(42.5 \%)$ reported a shortage of GP registrars, 26 HAs $(35.6 \%)$ reported no problems and 16 HAs $(21.9 \%)$ did not know whether problems existed.

Local vocational training schemes were seen by the HA respondents as the major source of new recruits to vacant GP principal posts, with 33 $(48.6 \%)$ having either some or major problems in retaining registrars on completion. Such trends were confirmed by directors of postgraduate GP education, eight of whom $(72.7 \%)$ commented that

Table 1 Postal survey response rates by NHS Executive regions

\begin{tabular}{|c|c|c|c|c|}
\hline NHS region & $\begin{array}{l}\text { Number of HAs } \\
\text { sampled }\end{array}$ & $\begin{array}{l}\text { Number of HAs that } \\
\text { responded }\end{array}$ & $\begin{array}{l}\text { Number of GP } \\
\text { directors sampled }\end{array}$ & $\begin{array}{l}\text { Number of GP } \\
\text { directors that } \\
\text { responded }\end{array}$ \\
\hline London & 16 & $12(75.0 \%)$ & 4 & $4(100 \%)$ \\
\hline South East & 14 & $9(64.3 \%)$ & 2 & $2(100 \%)$ \\
\hline South West & 8 & $4(50.0 \%)$ & 3 & $1(33.3 \%)$ \\
\hline Eastern & 9 & $7(77.8 \%)$ & 1 & - \\
\hline Trent & 11 & $7(63.6 \%)$ & 3 & $1(33.3 \%)$ \\
\hline West Midlands & 13 & $11(84.6 \%)$ & 1 & $1(100 \%)$ \\
\hline North West & 16 & $11(68.8 \%)$ & 2 & $1(50 \%)$ \\
\hline Northern and Yorkshire & 13 & $12(92.3 \%)$ & 2 & $1(50 \%)$ \\
\hline Total & 100 & $73(73.0 \%)$ & 18 & $11(61.1 \%)$ \\
\hline
\end{tabular}


certain HAs in their area could not retain GP registrars on completion of training.

\section{$G P$ principals}

Overall, 446 principal posts (or $2.6 \%$ of wholetime equivalent (WTE) posts available in these areas) were vacant at the time of the survey. Approximately $75 \%$ of responding HAs indicated that they had between one and 10 vacancies, with a small number (7.6\%) having 20-25 unfilled GP principal posts. Approximately $40 \%$ of HAs had vacancies for less than $2 \%$ of their posts, and $10.6 \%$ had no vacancies at all (see Table 2). In the 54 HAs which indicated how long the posts had been vacant, 222 of 371 posts $(59.8 \%)$ were vacant for more than 4 months. With regard to a requirement for additional GP posts, 32 HAs (45.1\%, $n=71$ ) said that these were needed, and 21 (29.2\%, $n=72$ ) had areas considered by the Medical Practices Committee (MPC) to be underdoctored.

For judgements about how widespread a crisis there is in the GP workforce, just three directors of postgraduate GP education (4.2\%) described major problems in recruiting new principals across their whole HA area. Furthermore, only one (1.4\%) reported similarly widespread problems with regard to retention. In 12 cases $(16.9 \%)$, retention problems were confined to specific localities within the HA. Similarly, a total of 32 HAs $(45.0 \%)$ reported that difficulties in recruiting new GP principals existed in some areas. However, 26 $(36.6 \%)$ and $21(29.6 \%)$ HAs, respectively, reported some problems across their whole area in recruiting new GP principals and retaining existing ones. Importantly, more HAs reported problems in

Table 2 Proportion of vacant posts for health authorities

\begin{tabular}{ll}
\hline $\begin{array}{l}\text { Vacancies as a percentage } \\
\text { of available whole-time } \\
\text { equivalent posts }\end{array}$ & $\begin{array}{l}\text { Number of health } \\
\text { authorities }^{\text {a }} \\
(n=66)\end{array}$ \\
\hline Zero vacancies & $7(10.6)$ \\
$\leq 1.0 \%$ & $11(16.7)$ \\
$1.1-2.0 \%$ & $15(22.7)$ \\
$2.1-3.0 \%$ & $10(15.2)$ \\
$3.1-4.0 \%$ & $12(18.2)$ \\
$4.1-5.0 \%$ & $5(7.6)$ \\
$>5 \%$ & $6(9.1)$ \\
\hline
\end{tabular}

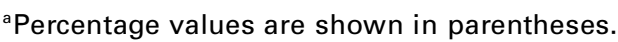

recruiting new GP principals than in retaining existing ones. Just 8 HAs $(11.3 \%, n=71)$ had no problems in recruiting new principals anywhere in their area, and 37 HAs $(52.1 \%)$ had no problems in retaining principals in post. Only six areas $(8.5 \%)$ had no problems with either recruitment or retention.

\section{Male and female GPS}

Table 3 lists reported problems with recruitment and retention among men and women GP principals. More HAs reported some or major problems in recruiting women compared with men $(66.2 \%$ vs. $49.3 \%)$. There was less of a contrast with regard to retention, with $37.5 \%$ and $33.8 \%$ of respondents reporting some or major problems among women and men, respectively.

\section{Ethnic minority GP principals}

A total of 67 HAs $(23.9 \%)$ said that they currently had some or major problems in recruiting GPs from ethnic minorities, and approximately $18 \%$ currently had problems in retaining them (see Table 3). A further $4.5 \%$ and $9 \%$ of HAs anticipated recruitment or retention problems, respectively, in the future.

\section{GP principals in the older age groups}

Table 4 shows that $18.3 \%$ of GPs in the responding HAs were within 10 years of retirement age, and $8.4 \%$ were within 5 years of that age. Standard retirement ages of 60 years for women and 65 years for men were used. Respondents reported that 220 doctors took early retirement in the months preceding the survey, one-third of whom had retired on ill-health grounds. Finally, only $4.4 \%$ of women and $2.0 \%$ of men had remained in practice beyond 60 and 65 years of age, respectively.

A total of 22 HAs (30.6\%) reported that the age profile of GP principals was not a problem for them. However, 40 HAs $(55.6 \%)$ reported that the high proportion nearing retirement had considerable implications for future turnover levels.

HAs were asked whether concerns about ethnicminority GP principals, who came from overseas in the 1960s and 1970s, and were now nearing retirement, were relevant in their area. A total of $33(53 \%)$ were not affected in this way, but 31 $(42.5 \%)$ reported that the large number of older ethnic-minority GP principals would constitute a 
Table 3 Scale of health authority problems in recruiting and retaining men, women and ethnic-minority GP principals

Number of health authorities ${ }^{\mathrm{a}}$

$\begin{array}{lllll}\begin{array}{l}\text { Major problems } \\ \text { exist now }\end{array} & \begin{array}{l}\text { Some problems } \\ \text { exist now }\end{array} & \begin{array}{l}\text { No problems exist } \\ \text { now but they are } \\ \text { likely in the future }\end{array} & \begin{array}{l}\text { and noblems exist } \\ \text { expect }\end{array} & \begin{array}{l}\text { Do not know } \\ \text { if problems } \\ \text { exist }\end{array}\end{array}$

\begin{tabular}{|c|c|c|c|c|c|}
\hline \multicolumn{6}{|c|}{ Recruitment of new GP principals } \\
\hline Women & $6(8.8)$ & $39(57.4)$ & $2(2.9)$ & $15(22.1)$ & $6(8.8)$ \\
\hline Men & $2(2.9)$ & $32(46.4)$ & $6(8.7)$ & $21(30.4)$ & $8(11.6)$ \\
\hline Ethnic groups & $2(3.0)$ & $14(20.9)$ & $3(4.5)$ & $31(46.3)$ & $17(25.4$ \\
\hline \multicolumn{6}{|c|}{ Retention of existing GP principals } \\
\hline Women & $2(2.8)$ & $25(34.7)$ & $6(8.3)$ & $30(41.7)$ & $9(12.5)$ \\
\hline Men & $1(1.4)$ & $23(32.4)$ & $7(9.9)$ & $32(45.1)$ & $8(11.3)$ \\
\hline Ethnic groups & - & $12(17.9)$ & $6(9.0)$ & $36(53.7)$ & $13(19.4$ \\
\hline
\end{tabular}

a Percentage values are shown in parentheses.

Table 4 Retirement trends in the GP principals' workforce reported by health authorities ${ }^{\mathrm{a}}$

\begin{tabular}{lccc}
\hline & Men & Women & Total \\
\hline GPs nearing retirement & & & \\
Total GP principals & 12416 & 5396 & 17812 \\
GP principals within 10 years of retirement & $2293(18.5 \%)$ & $962(17.8 \%)$ & $3263(18.3 \%)$ \\
GP principals within 5 years of retirement & $1024(8.2 \%)$ & $474(8.8 \%)$ & $1498(8.4 \%)$ \\
GP principals within 2 years of retirement & $423(3.4 \%)$ & $250(4.6 \%)$ & $673(3.8 \%)$ \\
GP principals over age 60 years for women and & $254(2.0 \%)$ & $235(4.4 \%)$ & $489(2.7 \%)$ \\
65 years for men & & & 220 \\
GPs taking early retirement in last 12 months & & & $73(33.2 \%)$ \\
Total individual GP principals who took early & 178 & 42 & $147(66.8 \%)$ \\
retirement & $62(34.8 \%)$ & $11(26.2 \%)$ & $31(73.8 \%)$ \\
GP principals who retire early on ill-health grounds & $116(65.2 \%)$ & & \\
GP principals who retired early but not on ill-health & & & \\
grounds & & & \\
\hline
\end{tabular}

a Table 4 is based on the workforce figures supplied by the 69 health authorities (61 in the case of early retirements) that responded to these questions. It assumes a general retirement age of 60 years for women and 65 years for men.

problem in the relatively near future. A further $4.1 \%$ stated that they did not know.

\section{Non-principals}

Problems were also reported with regard to the numbers of non-principals. Five HAs (7.5\%, $n=67$ ) had difficulty in filling GP associate posts, and 19 HAs $(27.1 \%, n=70)$ reported a shortage of GP assistants. Locums were in short supply in 37 HAs $(50.7 \%, n=73)$. Only 17 HAs $(23.3 \%)$ reported no problems at all, but a further 19 HAs
(26\%) did not know whether or not a locum shortage existed in their area.

\section{Reasons for GP recruitment and retention problems}

The reasons given in open-ended responses for recruitment and retention problems among registrars and principals were similar, and the results for principals are shown in Table 5. To some extent, problems were attributed to changes in the employment needs, expectations and con- 
Table 5 Health authority explanations for recruitment and retention problems among GP principals ${ }^{\mathrm{a}}$

Type of explanation

Number of health authorities

$\begin{array}{ll}\text { Women } & \text { Men } \\ \text { Recruitment Retention Total } & \text { Recruitment Retention Total Overall }\end{array}$

\section{Geographical area}

Deprived social area (e.g., inner city

5

or certain housing estates - high

workload/low incomes)

Unattractive area in which to live/work

(e.g., no cultural centre, major hospital,

university)

Personal safety concerns

High cost of living

Remote rural areas

Personal job needs and constraints of GPs Need for more flexible working than practices offer (e.g., part-time, job-share)

Family commitments (e.g., career breaks)

Need to avoid out-of-hours commitment

Prefer non-principal posts (e.g., more

flexible)

Younger GPs unwilling to invest long term

Pursuing alternative careers

Younger GPs more geographically mobile

Geographically mobile due to spouse's

career

High workload generally

Exploitation/expected to do 'women's

work'

New GPs want better income/immediate

parity

Earlier retirement

Generally low morale, work-related

stress or burnout

Pressure from NHS changes/patient

demands

$\begin{array}{rrrrrrr}5 & 3 & 8 & 6 & 3 & 9 & 17 \\ 2 & 2 & 4 & 1 & 1 & 2 & 6 \\ & & & & & & \\ -2 & 1 & 3 & - & - & - & 3 \\ 2 & - & 1 & 1 & 1 & 2 & 3 \\ & - & 2 & 1 & - & 1 & 3\end{array}$

$\begin{array}{rrrrrrr}22 & 9 & 31 & 1 & - & 1 & 32 \\ 6 & 7 & 13 & - & - & - & 13 \\ 2 & 1 & 3 & 1 & 1 & 2 & 5 \\ 1 & - & 1 & 2 & - & 2 & 3 \\ 8 & - & 8 & 6 & 2 & 8 & 16 \\ - & 3 & 3 & 2 & 7 & 9 & 12 \\ - & 3 & 3 & 2 & 2 & 4 & 7 \\ 1 & 4 & 5 & - & - & - & 5 \\ 3 & - & 3 & 3 & - & 3 & 6 \\ 2 & 1 & 3 & - & - & - & 3 \\ - & - & - & 1 & 1 & 2 & 2 \\ - & 5 & 5 & - & 9 & 9 & 14 \\ - & 6 & 6 & - & 6 & 6 & 12 \\ - & 3 & 3 & - & 6 & 6 & 9\end{array}$

General nature of recruitment process and application levels

General lack of quality applicants

nationally

Lack of male part-time applicants

$\begin{array}{rrrrrrr}9 & - & 9 & 11 & - & 11 & 20 \\ - & - & - & 1 & - & 1 & 1\end{array}$

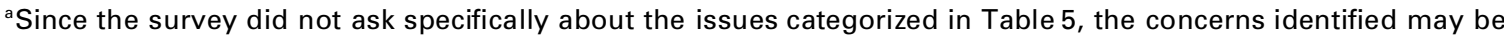
more widespread than the figures reported indicate.

straints of younger doctors (both men and women). These included the following:

1) a demand for more flexible working arrangements;

2) an unwillingness to take on and/or a wish to postpone financial commitment to a partnership;
3) their generally greater geographical mobility and increasing tendency to pursue careers outside general practice.

Overall, 9 HAs pointed to a national lack of quality women applicants, and $11 \mathrm{HAs}$ stated that men applicants were in short supply. It was noted 
that women tended to move as a result of their spouse's career rather than their own. Men were reported to be more likely than women to pursue alternative careers outside general practice. Flexible working conditions were a priority for HAs with a predominantly female workforce. 'In one locality a high proportion of younger GPs are women. Career breaks and flexible working need to be developed to ensure their retention'.

GPs' unwillingness to make a long-term investment in practice premises was felt by HAs to be of equal importance to both sexes. HAs also pointed to the more general pressures of wider NHS changes, as well as higher workload, low morale and stress as contributory factors to both recruitment and retention problems. For example, 'There are just not enough doctors wishing to move into general practice due to overwork and everchanging government agenda'. Another HA stated that 'Some GPs feel that they are coping less well than before. Changes due to government agenda have in some cases reversed policies which GPs had only just managed to master'.

Area-specific problems such as a lack of attractive living and working environments, high levels of social deprivation, lack of a cultural centre or major hospitals, and personal safety concerns were important, as were the associated difficulties of a lack of training practices and/or appropriate training to equip new GPs with the skills necessary to enable them to cope in such localities.

Finally, there was increasing reliance on European Union (EU)-qualified doctors undertaking vocational training in the UK to fill local vocational training schemes. The major problem was that EU doctors tended to return to their own country on completion of their training.

\section{Approaches to tackling GP recruitment and retention problems}

How are HAs and GP education directors tackling the problems cited above?

\section{Initiatives reported by directors of postgraduate GP education}

Perhaps not surprisingly, given the investment in postgraduate training made by directors of postgraduate education, they gave emphasis to initiatives designed to improve the retention of registrars. For example, there were initiatives with regard to improving the marketing, content and delivery of vocational training and the enhancement of post-vocational education. Also reported were adjustments to work roles and career structures (i.e., broadening the choice of employment arrangements, providing greater emotional support and providing more career variety and development opportunities). Finally, there was a range of more general activities, including re-entry training, recruitment fairs, information packs and newsletters.

\section{Initiatives reported by health authorities}

Recruitment and retention of GP registrars was also regarded by HAs as one of the main ways of ensuring an adequate workforce of GP principals. In total, $31(44 \%)$ and 17 (24\%) HAs reported the use or planned use, respectively, of schemes which were felt either to have spin-offs for or directly to impact on recruitment and retention. Most of them centred on improved training for GP registrars and recently qualified GPs. However, a minority of HAs were actively supporting continuing/refresher education for established principals and induction training for new partners. Only two HAs mentioned the provision of re-entry training for potential returners. The three others which focused on returners said that they were relying specifically on improvements to the GP retainer scheme.

As with directors of postgraduate GP education, the second set of recruitment and retention measures reported by HAs centred on GPs' work roles and career structures. Over $75 \%$ of HAs supported innovative GP posts, with $45 \%$ reporting initiatives in progress and $22 \%$ reporting firm plans for future developments. The most frequently mentioned scheme was for salaried GPs (42 respondents). In addition, 8 HAs reported combined academic/ research posts, two mentioned associate posts based in HA management, and two more pointed to the development of hospital clinical assistantships and community specialist posts, respectively.

Almost $70 \%$ of HAs had also used or were planning or discussing the use of measures to free up time for existing GP principals, including sabbatical and/or study leave schemes (14 respondents), protected time for other activities (11 respondents), the reduction of on-call duties by means of locum banks and out-of-hours co-operatives or deputizing services (14 respondents), and the provision of shadow partners specifically for retiring GPs to 
reduce their working hours, and for mid-career GPs to enable them to take a career break (3 respondents). One way of facilitating such changes was reported to be through the employment of salaried doctors.

Career support and development measures were in place in $46 \%$ of HAs, and were definitely to be funded in a further $10 \%$ of HAs. Support with regard to everyday working pressures centred mainly on peer support and mentoring and/or mutual support within peer groups. Stress management training, structured counselling programmes or occupational health services were mentioned by only 6 respondents.

Career development activities tended to focus on continuing education and/or locally tailored learning initiatives, including the development of university links (22 HAs). More widely organized measures focusing on planned personal development for GPs were much less common. Similarly, support for flexible working practices (currently undertaken by approximately $42 \%$ of HAs) tended to include less pro-active activities, such as information provision and general encouragement to practices to consider flexible options.

HAs also provided more general assistance either to doctors seeking work or to practices wishing to recruit new partners, such as a health authority-held database of GPs looking for work. However, this was often an $a d-h o c$ measure in response to ongoing enquiries alone. Only $12.5 \%$ of HAs were providing a more systematic matching service for the appropriate placement of new recruits. More than $44 \%$ and $43 \%$ of HAs, respectively, had at some time provided advertizing or marketing assistance to individual practices, or produced information packs to assist the recruitment process locally. However, only $16.7 \%$ had been involved in more widespread recruitment campaigns and/or fairs. In addition, many HAs that were involved in marketing and/or information provision said that these measures might be temporary, and were not always successful.

\section{Discussion}

The response rate of $73 \%$ from HAs was good for this type of study, where completing detailed questionnaires for researchers is not a priority activity for staff. The response to surveys from directors of postgraduate education was in line with that of GPs. In some cases, up to four reminders were necessary, but this was often because the questionnaire had been passed to someone else in the organization and had then been mislaid, rather than being due to any unwillingness to participate. In other cases the information held by HAs and available to directors of postgraduate education could not be disaggregated into the format requested in the questionnaire.

The data from this study confirm that many areas experience problems with GP recruitment and retention. However, these problems are not uniformly distributed, but are mainly concentrated in urban deprived areas. This does not mean that a national GP workforce crisis does not exist, but it serves to emphasize the importance of a more sophisticated analysis of workforce problems if effective solutions are to be developed.

HAs and directors of postgraduate education were very aware of the problems underlying recruitment and retention, such as trends towards earlier retirement, the impending large-scale retirement of overseas qualified ethnic-minority GPs in some areas, and a desire among new recruits to live and work in the more attractive areas. Employment opportunities in the GP labour market (in terms of a substantially full-time, long-term partnership commitment) also appear to be less attractive to the modern workforce. Particularly given the increasing female participation, respondents felt that there was a need to address career structures for the growing proportion of non-principals and part-time principals. Present systems for salaried GP employment were also regarded as underdeveloped. However, it remains to be seen whether new initiatives (e.g., under Personal Medical Services (PMS) pilots) will improve recruitment and retention in problem areas in the longer term.

The emphasis of directors of postgraduate education was on the retention of registrars by improving the experience of vocational training in terms of both course content and personal requirements. There was also an emphasis on improved marketing of courses to attract more recruits. HA initiatives focused on improved training for the recently qualified (as well as courses for established principals), the development of innovative posts (many salaried, including research opportunities and hospital assistantships), the availability of sabbaticals, study leave and locally tailored 
educational opportunities, a reduction in on-call requirements, and career support and stress management. Also available were informal databases of GPs looking for work, and information packs to enable practices to conduct their own recruitment and retention initiatives.

A reliance on EU-qualified doctors undertaking vocational training in the UK is partly a consequence of overproduction of doctors in some EU states and the free movement of workers within the EU. Many respondents with recruitment and retention problems were of the opinion that even if a registrar returned to their own country on qualification, they would have performed a useful function as registrars during the time that they were on the scheme. Not all of them returned to their own country, and it was felt that if some stayed, then this would add to the stock of GPs and would be worthwhile, particularly if schemes were unable to recruit from within the UK.

The high level of investment required by both directors of postgraduate education and HAs in their local vocational training schemes was regarded as important in allowing trainees to experience the benefits of the area, so encouraging them to take up posts locally on completion of their training. This was particularly important to schemes in inner-city areas, despite the fact that training schemes are a necessary part of a GP's education and are not designed for recruitment and retention purposes. HAs that are experiencing GP recruitment and retention problems may hope that an influx of registrars to a vocational training scheme will solve at least some of their problems, although in many cases such hopes have not been realized.

Above all, a greater commitment to long-term strategic planning is required at all levels. The respondents in our survey did report a number of changes which were tailored to local circumstances, and which directly addressed the need to accommodate the very different employment requirements of today's GP workforce. However, one important message is that many initiatives remain, of necessity, unco-ordinated and restricted by short-term budgetary constraints. A lack of strategic planning was evident where many initiatives to improve both recruitment and retention were piecemeal, short-term and implemented in response to - rather than in anticipation of - local difficulties. However, with increasing awareness of potential problems, it is possible that reactive crisis management will be replaced by more pro-active forward thinking. This is particularly so since PCG primary care investment plans are required to highlight problem areas in the local medical workforce and to set out plans to tackle imbalances. This should have the effect of enhancing strategic planning for the GP workforce, especially if local initiatives are fed back systematically to the national level for wider dissemination. However, in the mean time there is little room for complacency. The exodus or crisis may not have happened on a nationwide basis yet, but there are clear indications that changes are needed in order to offset problems in the relatively near future.

\section{Acknowledgements}

This study was funded by the Department of Health. The views expressed are those of the authors but not necessarily those of the Department of Health.

\section{References}

British Medical Association 1998: Memorandum of Evidence to the Review Body on Doctors' and Dentists' Remuneration. London: British Medical Association.

Calman, M. and Williams, S. 1995: Challenges to professional autonomy in the United Kingdom? The perceptions of general practitioners. International Journal of Health Services 25, 219-41.

Carlowe, J. 1998: Doctors shunning general practice. Pulse 18 April, 20.

Chambers, R., Wall, D. and Campbell, I. 1996: Stresses, coping mechanisms and job satisfaction in general practitioner registrars. British Journal of General Practice 46, 343-48.

General Medical Services Committee 1996: Medical Workforce Task Group Report. London: British Medical Association.

General Medical Services Committee 1998. Annual Report. London: British Medical Association.

Kernick, D. 1995: GPs' low morale. British Journal of General Practice 45, 445.

Leese, B. and Young, R. 1999: Disappearing GPs: is there a crisis in recruitment and retention of general practitioners in England? Debates in Primary Care No. 3. Manchester: National Primary Care Research and Development Centre, University of Manchester.

McKinnon, J., Townsend, J. and Walker, Z. 1999: Primary care: past and future. Health Services Management Research 12, $143-48$. 
Review Body on Doctors' and Dentists' Remuneration 1996: Twenty-Fifth Report. London: HMSO.

Review Body on Doctors' and Dentists' Remuneration 1998: Twenty-Seventh Report. London: The Stationery Office.

Royal College of General Practitioners 1996: The primary care workforce. A descriptive analysis. London: Royal College of General Practitioners.

Young, R. and Leese, B. 1999: The recruitment and retention of general practitioners in the UK: what are the problems and solutions? British Journal of General Practice 49, 829-33. 